\title{
MATRIX STRENGTH INFLUENCE ON COMPOSITE FIBRE REINFORCED CONCRETE BEHAVIOUR IN FLEXURE AND SINGLE FIBRE PULL-OUT
}

\author{
Arturs Lukasenoks, Arturs Macanovskis, Andrejs Krasnikovs \\ Riga Technical University, Latvia \\ arturs.lukasenoks@rtu.lv, arturs.macanovskis@rtu.lv, andrejs.krasnikovs@rtu.lv
}

\begin{abstract}
Composite glass and carbon fibres were used to investigate fibre reinforced concrete behaviour and single fibre pull-out resistance depending on concrete matrix strength. Composite fibres with smooth surface, uneven and undulated shape were used. Fibre diameters were from 1.52 to $2.18 \mathrm{~mm}$ and $50 \mathrm{~mm}$ length. Three different concrete matrices were developed with low, average and high compressive strength. Concrete consistency (slump flow), compressive strength development and shrinkage were measured to characterize concrete matrices. Beam samples $(100 \times 100 \times 400 \mathrm{~mm})$ with 1.5 vol. \% of fibres were manufactured and tested in four-point bending. Force was measured and deflection in the middle of the span. Bending test results and bending behaviour were analysed as well as the number of fibres in the crack plane. Composite fibre reinforced concrete behaviour in flexure was compared with known straight and undulated steel fibres with the same dosage. Composite fibres show significantly smaller first crack strength compared to steel fibres, but contrary to steel fibres they show stable strain hardening after the first crack in both concrete matrices - with high and average strength. Tested fibre reinforced concretes show strain softening in the low strength concrete matrix. Single fibre pull-out samples were manufactured to investigate the matrix strength influence on pull-out resistance. Fibre peak pull-out force for smooth composite fibres increases significantly, when the concrete matrix strength increases. Pull-out force for rough surface fibres is initially very high in low strength concrete matrices and rises relatively less, when the strength increases compared to smooth fibres.
\end{abstract}

Keywords: composite fibre, fibre pull-out, high strength concrete.

\section{Introduction}

Fibre reinforced concrete (FRC) is a material with short fibres chaotically oriented in the concrete matrix volume. Such material has higher (compared with conventional concrete reinforced by steel rebars) impact resistance, wear resistance. FRC is very attractive in a technological sense by simplifying the construction element production technology; fibres are introduced in the mixer on the concrete truck afterwards poured in the mould. Steelfibre type is used most commonly as disperse reinforcement in structural applications with different geometrical shapes and sizes[1-4]. Fibres can be straight or deformed to increase pull-out resistance (with hooks on the ends, undulated etc.). Polymer fibres have much lower stiffness and strength compared to steel, and they mainly are used to reduce the shrinkage cracking in structural elements [5]. The properties of polymer fibres have been improved constantly, and information about high - strength polymer fibres has already appeared [6]. Other types of synthetic fibres such as glass, basalt, aramid, and carbon have a high strength, stiffness, and low specific gravity. These fibres are chemically stable in severe environmental conditions. Unfortunately, due to the small diameter of glass, basalt, aramid, and carbon fibres, it is difficult to introduce them into concrete. The fibres form clews and rolls, when mixing them into the concrete with conventional techniques (using slowspeed mixers). This problem becomes more pronounced with increased dosage of the fibres. All mentioned fibres are split or torn in shorter pieces, when mixed with concrete in high-speed mixers [7]. Fibres from E- and S- glass are chemically unstable in alkali environments. In recent years, investigations in composite materials have contributed greatly to the manufacturing technology of composite and fibre materials, which has reduced their cost and increased their use. Very few information on composite fibres is found. Unidirectional basalt fibre - polymer matrix composite elements with a rectilinear geometry and round, smooth cross sections (Minibar ${ }^{\mathrm{TM}}$ ) now are available on the market (similar product to composite fibres). Basalt Minibar fibres are recommended for use in high volume fractions (1.5-3\%) to achieve tangible results [8; 9]. Long carbon fibres impregnated with epoxy resin are used to increase the impact resistance of concrete plates [10; 11]. Fibre reinforced concrete is required to provide resistance in the visible crack formation (pre-crack behaviour) and show quasi-constant load bearing until the visible macro crack reaches opening in the range of 2.5-3.5mm [12-14]. Such material mechanical behaviour demands every single fibre, which is crossing the macro crack, to have a pull-out diagram that shows quasi-constant (or even increasing) "plato". Mentioned studies of fibre reinforced concrete and fibre pull-out focus on one specific concrete matrix type and strength. Current research presents study with three different concrete matrix 
strength levels. Each matrix strength level represents a group of concretes that are used in the concrete and construction industry. Low strength concrete in the study represents the group of concretes with the compressive strength range 30-40 MPa used mostly for pavements, floors, foundations. Medium strength concrete in the range of 50-75 MPa represents a group of concretes used widely in precast industry for walls, prestressed beams, plates, bridge decks, roads. High strength concrete in the range of $90-125 \mathrm{MPa}$ is used relatively less than the previous two groups, and is used in precast industry for mock-up façade elements, heavy loaded beams, balconies, thin plates and sheets.

\section{Methodology}

\section{Concrete matrix}

Three concrete matrices were used with mix design as described in the paper [15]. Matrices were used to have three different concrete compressive strength levels - high (M1 - $125 \mathrm{MPa}$ ), medium (M2 - $70 \mathrm{MPa}$ ) and low (M3 - $35 \mathrm{MPa}$ ) compressive strength.

\section{Composite fibres}

Eight different carbon and glass composite fibres were used in this investigation: CF1 (24k filaments, $1.77 \mathrm{~mm}$ diameter), CF1-A (16k filaments, $1.3 \mathrm{~mm}$ diameter), CF1-B (8k filaments, 0.89 $\mathrm{mm}$ diameter), CF2 (24k filaments, $2.1 \mathrm{~mm}$ diameter), CF2-A (16k filaments, $1.79 \mathrm{~mm}$ diameter), CF2-B (8k filaments, $1.57 \mathrm{~mm}$ diameter), CF3 (24k filaments, $1.82 \mathrm{~mm}$ diameter) and GF2 (1.52 mm diameter). Main fibre types - CF1, CF2, CF3 and GF2 are presented in Fig. 1. Manufacturing process of the fibres is presented in the paper [15].

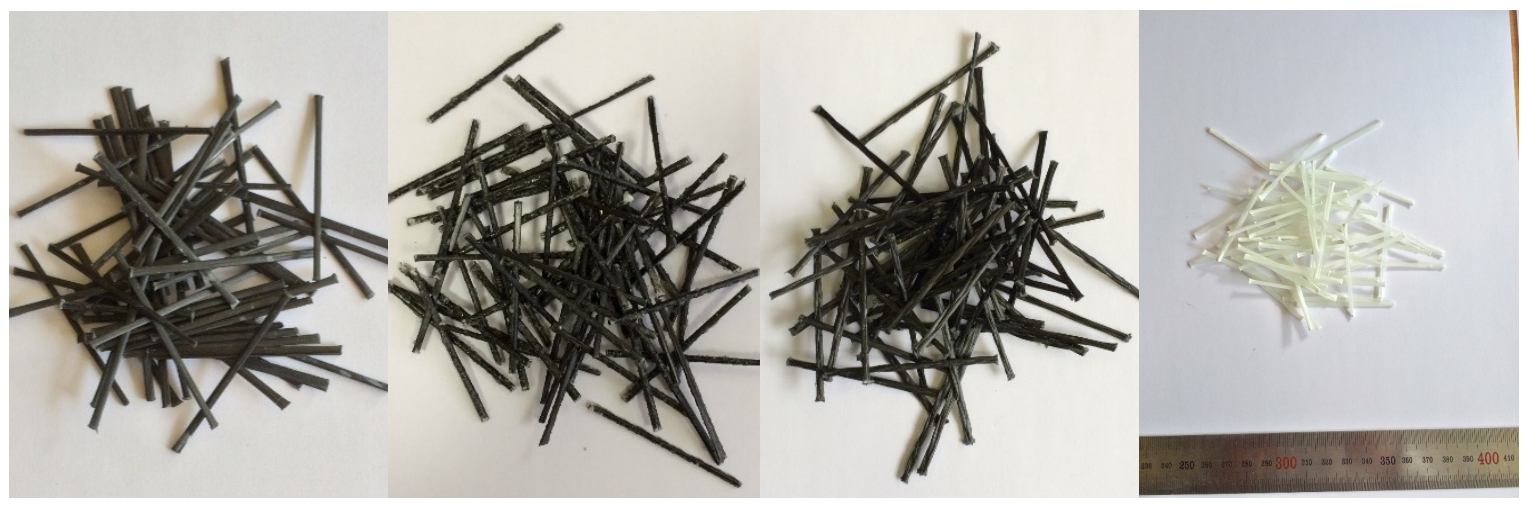

Fig. 1. Composite carbon fibres: CF1, CF2, CF3 and GF2 (from the left)

\section{Pull-out tests}

Composite fibre configuration was set to 0-degree angle to pull-out force and $25 \mathrm{~mm}$ embedment depth to investigate the concrete matrix strength influence on single fibre pull-out behaviour. Set of 7 samples was prepared for each fibre type and concrete matrix. Totally 168 pull-out samples were prepared. Composite carbon fibres with smooth surface $\mathrm{CF} 1, \mathrm{CF} 1-\mathrm{A}, \mathrm{CF} 1-\mathrm{B}$ and rough surface $\mathrm{CF} 2$, CF2-A, CF2-B as well braided composite carbon fibre CF3 and smooth glass fibre GF2 were used to investigate the concrete strength influence on pull-out. Pull-out samples with the size: $80 \times 100 \mathrm{x}$

$30 \mathrm{~mm}$ were used as shown in
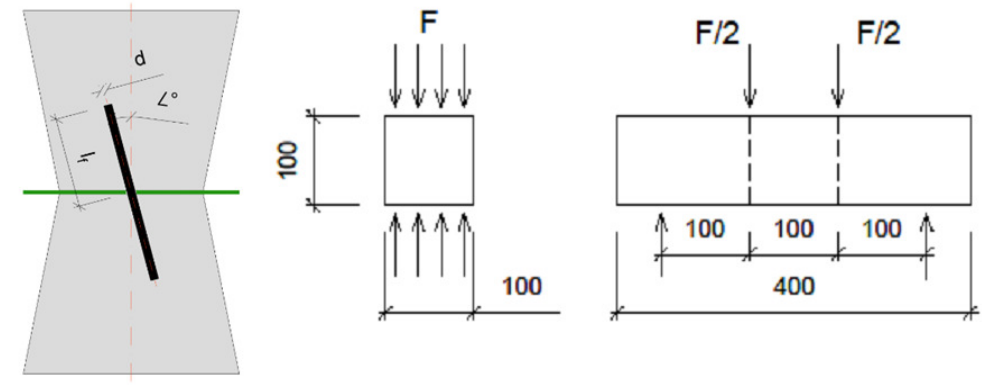

Fig. 2 on the left.

Beam tests 
Beam samples (100 x $100 \times 400 \mathrm{~mm})$ with 1.5 vol. \% of fibres were manufactured and tested in four-point bending to investigate fibre reinforced concrete behaviour in flexure.Set of 4 samples for each fibre type and concrete matrix was prepared (totally 24). Composite fibres CF1 and GF2 are used in beam samples. Load and deflection in the middle span was measured during the test. Tests were carried out with the load rate $0.25 \mathrm{~mm} / \mathrm{min}$. Load scheme is shown in
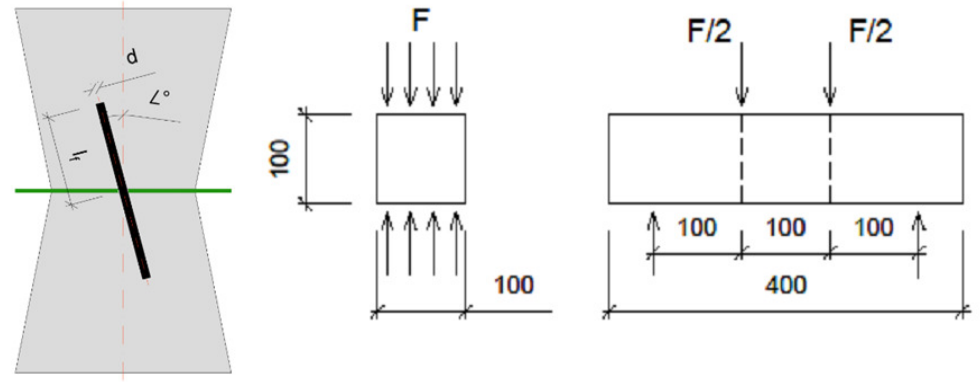

Fig. 2 in the middle and on the right.

Average pull-out curves are calculated and presented in the paper. Calculation process is the following: displacements starting with displacement $0 \mathrm{~mm}$ are increased with $0.05 \mathrm{~mm}$ and average corresponding load is calculated. Error is shown as standard deviation of the results.
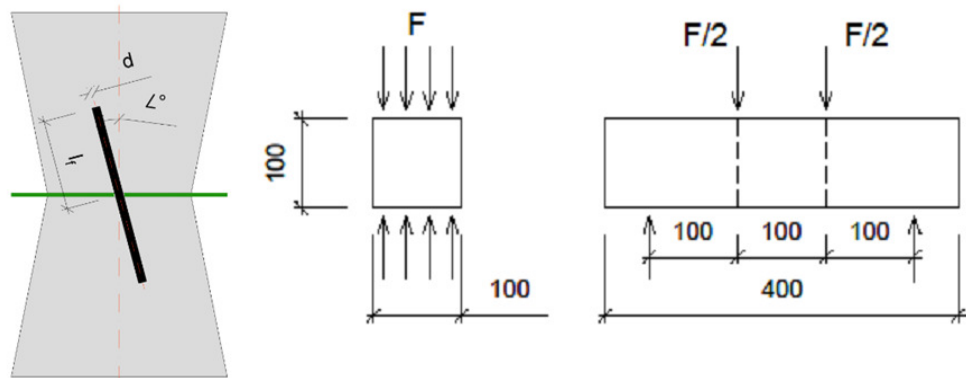

Fig. 2. Experimental testing of beams in four-point bending (on the right) single fibre pull-out sample (on the left)

\section{Results and Discussion}

Average pull-out test results for single straight, smooth composite fibre CF1 and straight, rough surface fibre CF2 in concrete matrices M1, M2 and M3 are presented in Fig. 3.
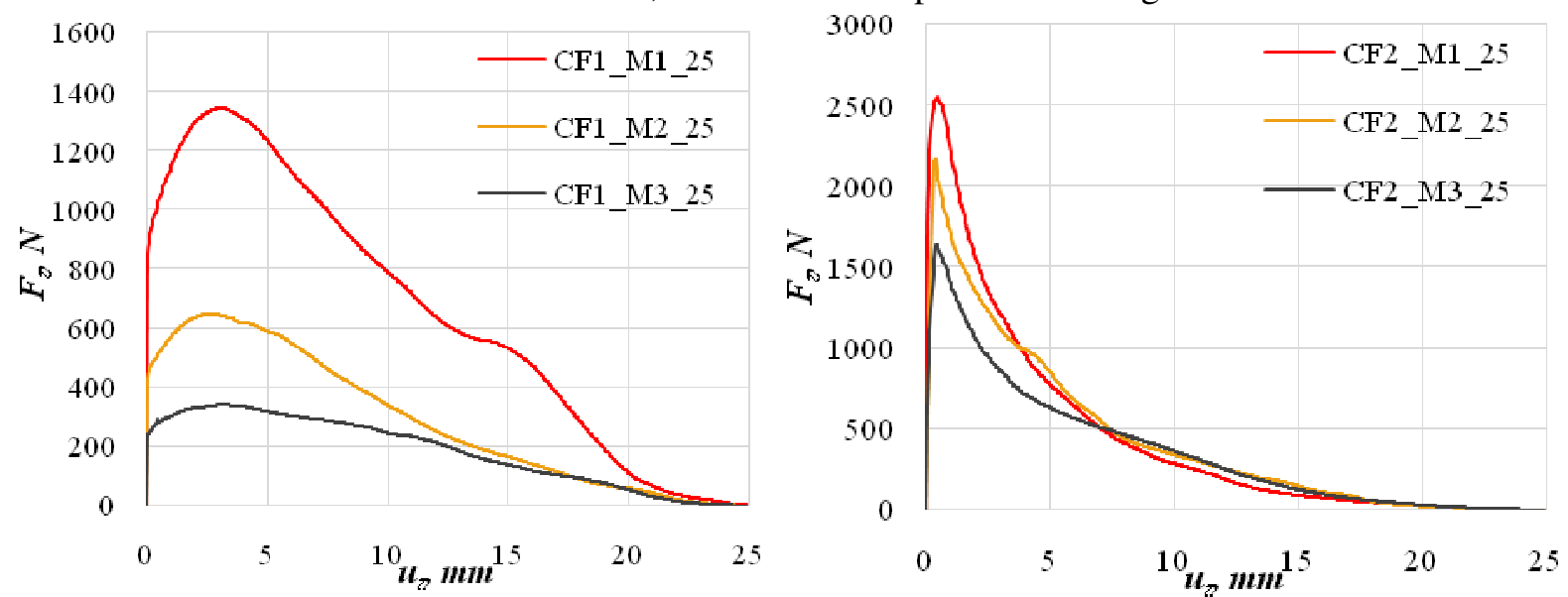

Fig. 3. Concrete matrix (M1, M2 and M3) influence on single composite fibre pull-out behaviour: $\mathrm{CF} 1$ (on the left), $\mathrm{CF} 2$ (on the right)

From the figure it is obvious that smooth fibre CF1 has significant resistance growth with the concrete compressive strength increase. Composite fibre CF2 has also higher peak pull-out force with the concrete strength increase, but there is evident sharp load fall after reaching the peak. 
Average pull-out test results for single straight, smooth composite fibre CF1-A and straight, rough surface fibre CF2-A in concrete matrices M1, M2 and M3 are presented in Fig. 4.
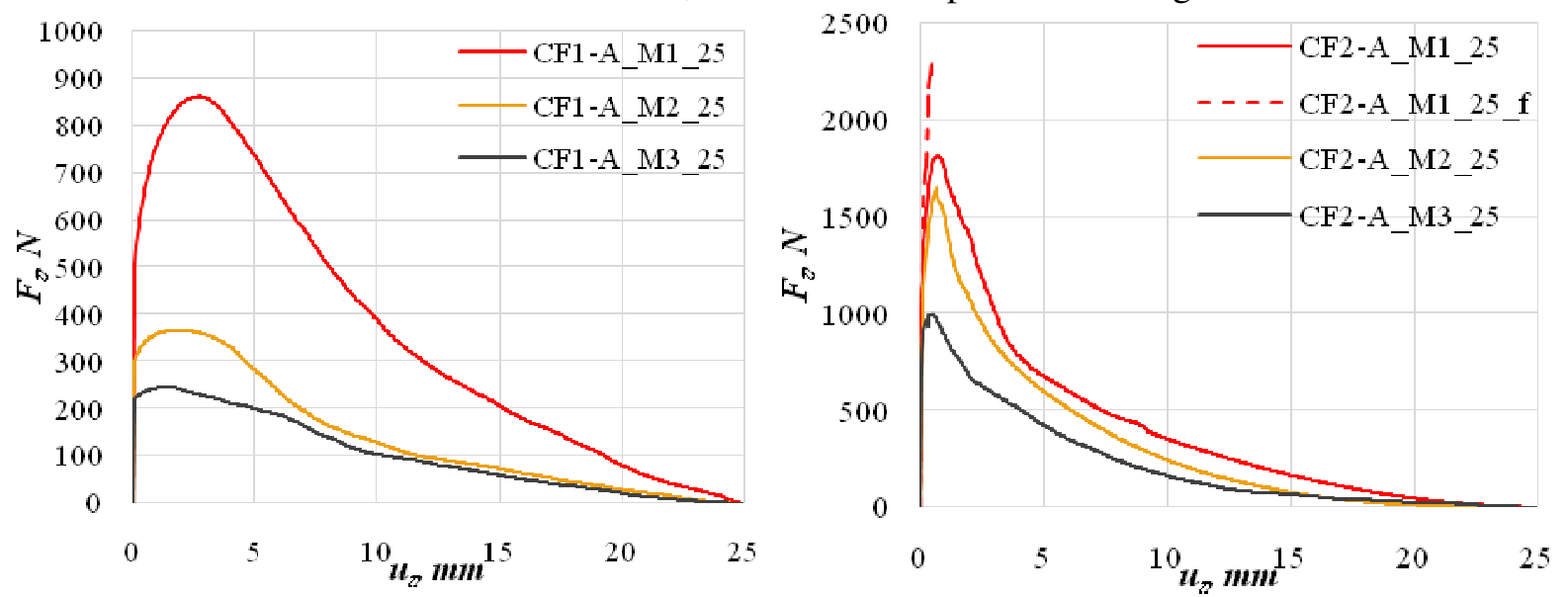

Fig. 4. Concrete matrix (M1, M2 and M3) influence on single composite fibre pull-out behaviour: CF1-A (on the left), CF2-A (on the right)

Higher concrete matrix compressive strength significantly influences the fibre pull-out resistance. Pull-out resistance is higher for the concrete matrix with higher compressive strength and this is more pronounced in the smooth fibre case - CF1-A. Peak pull-out force is higher also with the matrix strength increase for CF2-A fibre, however, there is a margin, when CF-A fibre is failing to pull-out and rupture occurs. Fibre rough surface with high compressive strength concrete produces substantial anchorage and the force exceeds the fibre tensile strength. The fact that some of CF2-A fibres at $25 \mathrm{~mm}$ embedment are failing and some pulling out form the concrete matrix is due to fibre surface deviations. Fibre layer that produced surface roughness is not uniform.

Average pull-out test results for single straight, smooth composite fibre CF1-B and straight, rough surface fibre CF2-B in concrete matrices M1, M2 and M3 are presented in Fig. 5.
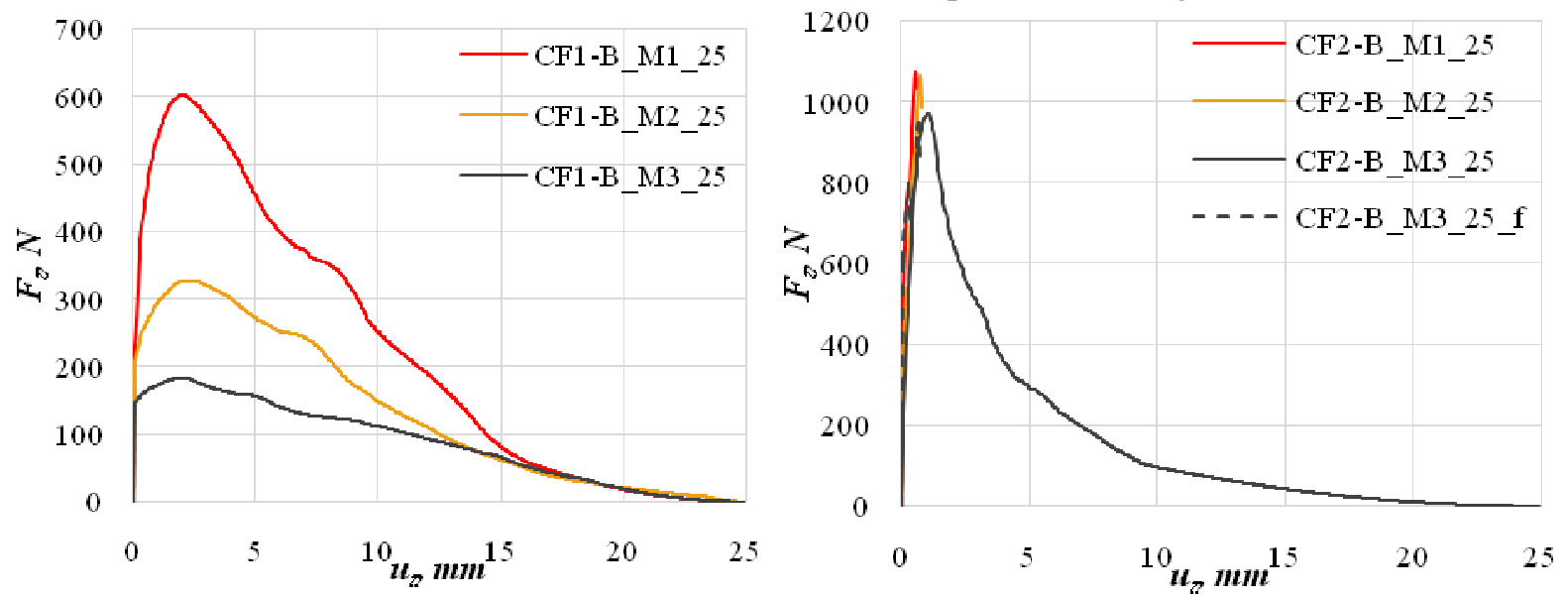

Fig. 5. Concrete matrix (M1, M2 and M3) influence on single composite fibre pull-out behaviour: CF1-B (on the left), CF2-B (on the right)

Similar to CF1 and CF1-A, it can be seen from the figure that smooth fibre CF1-B has also significant resistance growth with the concrete compressive strength increase. Composite fibre CF2-B has high anchorage in all three concrete matrices, the peak pull-out force exceeding $980 \mathrm{~N}$ results in fibre rupture. Rough composite fibre CF2-B in concrete matrix M3 does both - pulls out from the concrete and fails. This is mainly related to deviations in the fibre surface roughness and due to hand manufacturing in laboratory conditions.

Average pull-out test results for single braided composite carbon fibre CF3 and straight, smooth surface glass fibre GF2 in concrete matrices M1, M2 and M3 are presented in Fig. 6. 

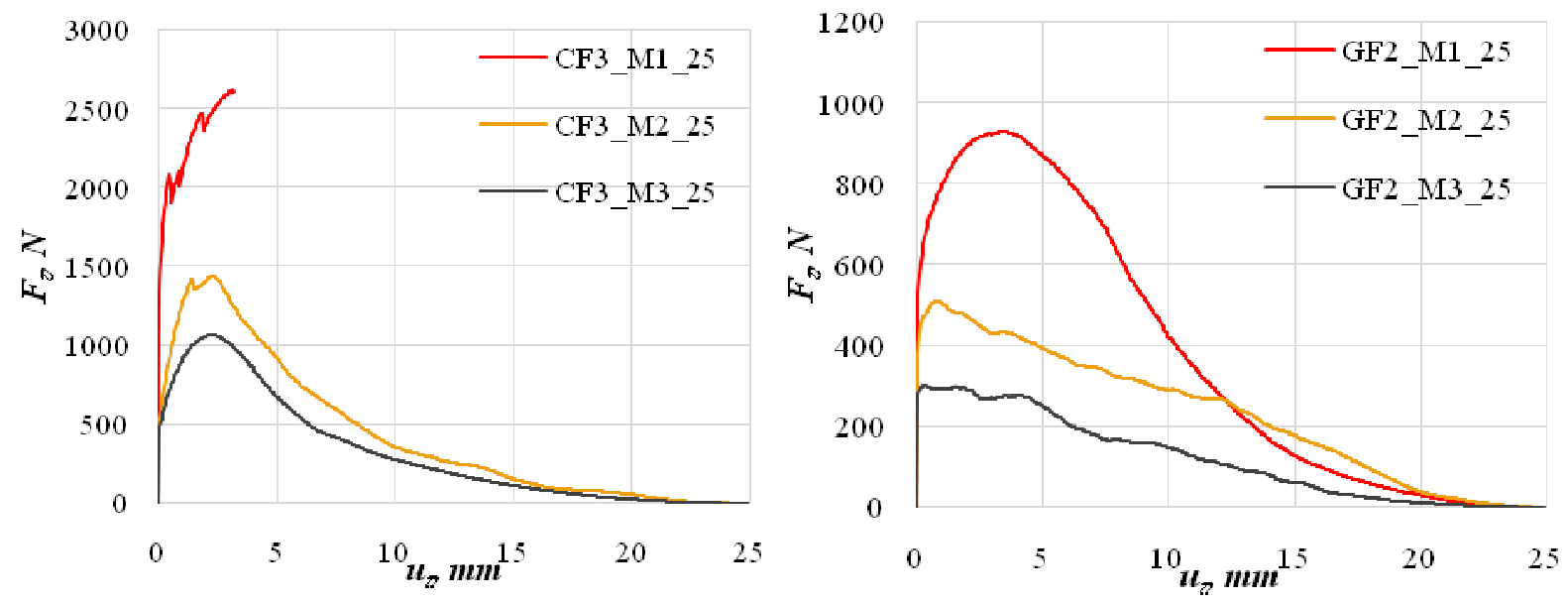

Fig. 6. Concrete matrix (M1, M2 and M3) influence on single composite fibre pull-out behaviour: $\mathrm{CF} 3$ (on the left), GF2 (on the right)

Average bending curves for samples with composite fibre CF1 (diameter $-1.77 \mathrm{~mm}$, length $50 \mathrm{~mm}$ ) and concrete matrices M1, M2 and M3 are presented in Fig. 7.

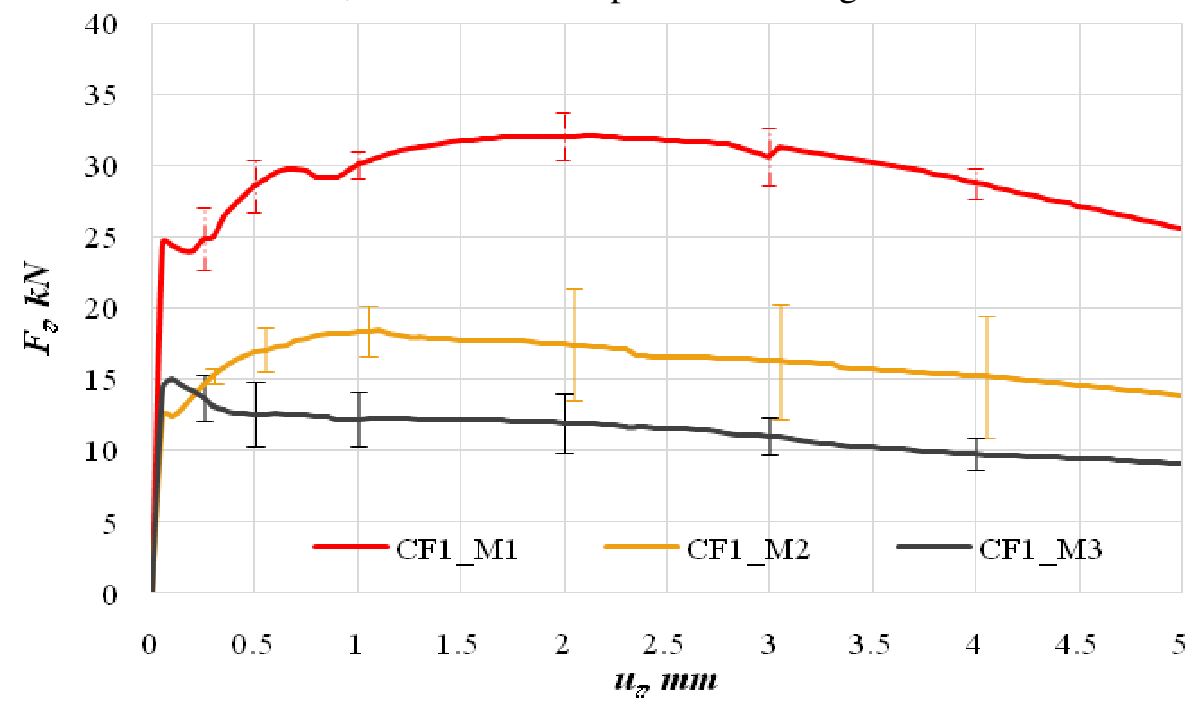

Fig. 7. Average load - deflection curves for beams subjected to bending with composite fibre CF1 in concrete matrices M1, M2 and M3

From the figure it can be observed that M2 and M3 with composite fibres CF1 have very similar load level, when the first crack appears - approximately $14-15 \mathrm{kN}$. Peak load is reached before the first crack in the concrete matrix M3. Peak load $-18.5 \mathrm{kN}$ is reached at approximately $1.1 \mathrm{~mm}$ deflection for the concrete matrix M2. First crack in the concrete matrix M1 is at $66 \%$ higher load compared to M2 and M3. Load increase after the first crack is gradual up to approximately $2 \mathrm{~mm}$ of deflection. Both reinforced concretes M1 and M2 can be classified as a material with strain hardening behaviour in flexure. Bending characteristic values for CF1 are presented in Table 1 as force and bending energy at 0.5 and $2.5 \mathrm{~mm}$ deflection points. Bending energy influence at $0.5 \mathrm{~mm}$ deflection is very little by the concrete matrix strength M2, M3 in the range $40-75 \mathrm{MPa}$, but is significantly increased (by $83 \%$ ) in M1. Bending energy at $2.5 \mathrm{~mm}$ deflection is increased by $35 \%$ for M2 compared to M3 and by $70 \%$ for M1 compared to M2. Load change in percentage is calculated, how the load is increased or decreased at $2.5 \mathrm{~mm}$ deflection point compared to $0.5 \mathrm{~mm}$. Test results in the research [16] with similar smooth long carbon fibres and concrete matrix with strength similar to M2 show approximately the same peak deflection force, but bending behaviour is strain softening.

Table 1

Bending characteristic values and bending energy for composite fibre CF1 in concrete matrices M1, M2 and M3 


\begin{tabular}{|c|c|c|c|c|c|c|}
\hline \multirow{2}{*}{$\begin{array}{c}\text { Fibre } \\
\text { type }\end{array}$} & \multicolumn{5}{|c|}{ Load, kN } & \multicolumn{2}{c|}{ Bending energy, kNmm } \\
\cline { 2 - 7 } & Peak load & $\mathbf{0 . 5 m m}$ & $\mathbf{2 . 5 m m}$ & Load change, \% & $\mathbf{0 . 5 m m}$ & $\mathbf{2 . 5 m m}$ \\
\hline CF1_M1 & 32.07 & 28.56 & 31.77 & $11.3 \%$ & 12.86 & 75.15 \\
\hline CF1_M2 & 18.49 & 16.89 & 16.61 & $-1.7 \%$ & 7.37 & 42.64 \\
\hline CF1_M3 & 15.01 & 12.58 & 11.60 & $-7.7 \%$ & 6.78 & 31.01 \\
\hline
\end{tabular}

Average bending curves for samples with composite fibre GF2 (diameter $-1.52 \mathrm{~mm}$, length $50 \mathrm{~mm}$ ) and concrete matrices M1, M2 and M3 are presented in Fig. 8.

First crack appearance is the same $-21.1 \mathrm{kN}$ for M2 and M3 matrices with GF2 fibre, similarly to CF1 fibres. Fibre reinforced concrete with M3 matrix performance is strain softening in flexure. Gradual decrease of load is observed throughout the bending right after the first crack appearance. Different behaviour is observed for the same fibre in the concrete matrix M2, were load increase is happening after the first crack. Load is increasing approximately up to $1.7 \mathrm{~mm}$ deflection reaching almost $26 \mathrm{kN}$. Very unusual behaviour of GF2 fibre is in the M1 matrix. Due to the concrete matrix strength and fibre pull-out resistance in the matrix, the fibre tensile strength is not sufficient. There can be observed stepwise load decrease at the beginning of the curve (at $0.2-0.7 \mathrm{~mm}$ of deflection). Right after reaching the peak there is sharp decrease in the load bearing capacity due to fibre failure (fibres are failing on by other).

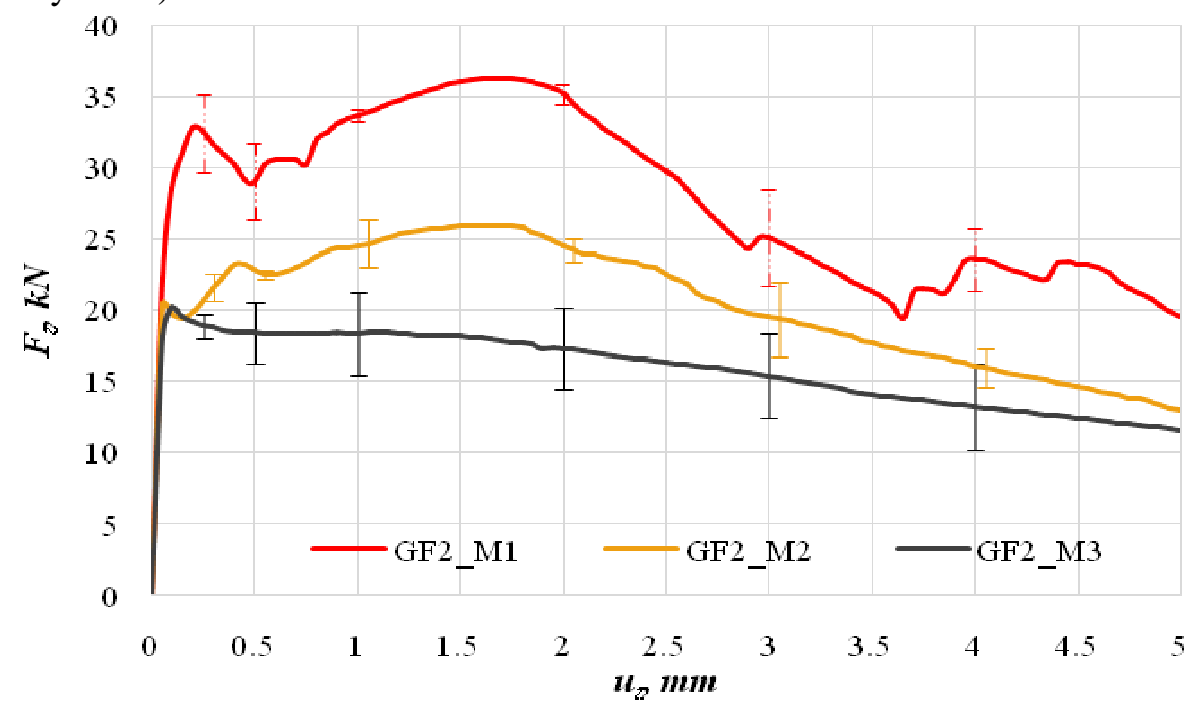

Fig. 8. Average load - deflection curves for beams subjected to bending with composite fibre GF2 in concrete matrices M1, M2 and M3

Bending characteristic values for GF2 are presented in Table 2 as the force and bending energy at 0.5 and $2.5 \mathrm{~mm}$ deflection points. Bending energy influence at $0.5 \mathrm{~mm}$ deflection is very little by the concrete matrix strength M2, M3 (approximately $13 \%$ ), but is significantly increased (by $39 \%$ ) in M1. Bending energy at $2.5 \mathrm{~mm}$ deflection is increased by $32 \%$ for M2 compared to M3 and by $37 \%$ for M1 compared to M2.

Table 2

\section{Bending characteristic values and bending energy for composite fibre GF2 in concrete matrices M1, M2 and M3}

\begin{tabular}{|c|c|c|c|c|c|c|}
\hline \multirow{2}{*}{ Fibre type } & \multicolumn{4}{|c|}{ Load, kN } & \multicolumn{2}{c|}{ Bending energy, kNmm } \\
\cline { 2 - 7 } & Peak load & $\mathbf{0 . 5 m m}$ & $\mathbf{2 . 5 m m}$ & Load change, \% & $\mathbf{0 . 5 m m}$ & $\mathbf{2 . 5 m m}$ \\
\hline GF2_M1 & 36.33 & 28.99 & 29.74 & $2.6 \%$ & 14.90 & 82.28 \\
\hline GF2_M2 & 25.97 & 22.87 & 22.47 & $-1.7 \%$ & 10.68 & 59.68 \\
\hline GF2_M3 & 20.20 & 18.43 & 16.33 & $-11.4 \%$ & 9.44 & 45.02 \\
\hline
\end{tabular}

\section{Conclusions}


Smooth fibres (CF1, CF1-A and CF1-B) have significant relation between the pull-out resistance and concrete compressive strength. Pull-out resistance and pull-out energy were $35-91 \%$ higher with the concrete matrix compressive strength increase from M3 (40 MPa) to M2 (75 MPa), and 61-125\% higher from M2 (75 MPa) to M1 (125 MPa). Pull-out resistance increase is the highest for the M1 concrete matrix. Also, the effect of the concrete compressive strength influence on pull-out behaviour can be observed on rough surface fibres (CF2, CF2-A and CF2-B), but increase in the pull-out force and energy is smaller: $6.4-18.4 \%$ increase for M2 compared to M3 and 3.8-29\% increase for M1 compared to M2. Some of the fibre (CF2-A, CF2-B and CF3) anchorage was exceeding the fibre tensile strength in the concrete matrix M1 and fibres fail to pull-out.

Composite glass fibre GF2 performs very well in low and average strength concrete matrices (M2 and M3). GF2 in the matrix M1 is not performing very well due to insufficient fibre tensile strength.

Concrete matrix compressive strength has strong influence on bending behaviour of FRC with composite fibres. It is also clearly visible that the tensile strength of composite fibre GF2 is completely utilized concrete in the matrix strength M1 (125 MPa) and even exceeded - stepwise load drops in the force-deflection curve indicated that fibre failure occurs. Therefore, fibre reinforced concrete with the matrix M1 and fibre GF2 becomes ineffective - sharp decrease of the load bearing capacity after reaching the peak. This clearly indicates that high strength concrete matrices have to be reinforced with high strength fibres to achieve a reliable material with strain hardening properties.

\section{Acknowledgements}

In accordance with the contract No. 1.2.1.1/16/A/005 between "Competence center of smart materials and technologies" Ltd. and the Central Finance and Contracting Agency, concluded on $26^{\text {th }}$ of September, 2016, the study is conducted by "MB Betons" Ltd. with support from the European Regional Development Fund (ERDF) within the framework of the project "Competence center of smart materials and technologies".

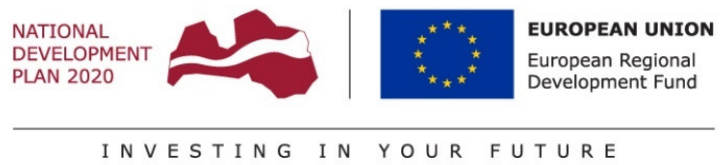

\section{References}

[1] Mobasher B., Li C. Modeling of stiffness degradation of the interfacial zone during fiber debonding. Journal of Compos. Eng., vol. 5, no. 10-11, 1995, pp. 1349-1365.

[2] Bernard E.S. Behavior of round steel fibre reinforced concrete panels under point loads. Mater Struct 33(3), 2000, pp. 181-188

[3] Naaman A. E. Engineered Steel Fibers with Optimal Properties for Reinforcement of Cement Composites Journal of Advanced Concrete Technology Vol. 1, No. 3, November 2003, pp. 241252.

[4] Banthia N., Trottier J.-F. Concrete Reinforced with Deformed Steel Fibers, Part I: Bond-Slip Mechanisms Tīle no. 91-M43 ACI Materials Journal , V. 91, No. 5, September-October 1994. pp. 435-446.

[5] Naaman A., Wongtanakitcharoen T., Hauser G. Influence of different fibers on plastic shrinkage cracking of concrete, ACI Mater J, vol 32, 2, 2005, pp. 102-107.

[6] Winterberg R., Durability of Fiber Reinforced Concrete. Part 1 - Corrosion, [online][03.08.2016] Available: http://www.elastoplastic.com/durability-of-frc-part-1-corrosion.

[7] Sahmenko G., Krasnikovs A., Lukasenoks A., Eiduks M. "Ultra High Performance Concrete Reinforced with Short Steel and Carbon Fibers." In: Environment. Technology. Resources: Proceedings of the 10th International Scientific and Practical Conference, Latvia, Rezekne, June18-20, 2015, pp.193-199.

[8] Miller P., Standal A. "Basalt FRP Minibar reinforced concrete", Fibre Concrete 2013, September 12-13, 2013, Prague, Czech Republic

[9] Miller P., Standal A. "Fiber reinforced concrete made from Basalt FRP Minibar", Proceedings of the 1st Concrete Innovation Conference (CIC), 11-13 June 2014, Oslo, Norway, ISBN 978-828208-0415 
[10] Tabatabaei Z.S., Volz J.S., Keener D.I., Gliha B.P. "Comparative Impact Behavior of Four Long Carbon Fiber Reinforced Concretes," Materials \& Design, V. 55, March 2014, pp. 212-223

[11] Tabatabaei Z. S., Volz J. S., Baird J., Gliha B.P., Keener D. I. Experimental and numerical analyses of long carbon fiber reinforced concrete panels exposed to blast loading. International Journal of Impact Engineering, 57, 2013, pp. 70-80.

[12]DAfStB. 2003. RichtlinieStahlfaserbeton [Technical guidelines for steel fiber reinforces concrete], part 1-4. DeutscherAusschussfürStahlbetonim DIN. Berlin

[13] Vandewalle L. et al. Recommendation of RILEM TC 162-TDF: test and design methods for steel fibre reinforced concrete: s-e design method (final recommendation). Mater Struct 36, 2003, pp. 560-567.

[14]CNR-DT 204, Guidelines for design, construction and production control of fibre reinforced concrete structures. National Research Council of Italy, Italy, 2006.

[15]Lukasenoks A., Macanovskis A., Krasnnikovs A., Lapsa V. Composite Fiber Pull-Out in Concretes with Various Strengths. In: 15th International Scientific Conference "Engineering for Rural Development": Proceedings. Vol.15, Latvia, Jelgava, 25-27 May, 2016. Jelgava: 2016, pp. 1417-1423.

[16]Zahra S., Tabatabaei J.S., Volz J.B., Gliha B.P., Darwin I. Keener, Experimental and numerical analyses of long carbon fiber reinforced concrete panels exposed to blast loading,International Journal of Impact Engineering, Volume 57,2013, pp. 70-80. 